\title{
The effect of aldose reductase inhibitors on glomerular prostaglandin production and urinary albumin excretion in experimental diabetes mellitus
}

\author{
W.P. Chang ${ }^{1}$, E.Dimitriadis ${ }^{1}$, T. Allen ${ }^{2}$, M.E.Dunlop ${ }^{1}$, M. Cooper ${ }^{2}$ and R. G. Larkins $^{1}$ \\ ${ }^{1}$ University of Melbourne Department of Medicine, Royal Melbourne Hospital, Victoria, \\ ${ }^{2}$ University of Melboume Department of Medicine, Austin Hospital, Heidelberg, Victoria, Australia
}

\begin{abstract}
Summary. The effect of two structurally unrelated aldose reductase inhibitors, sorbinil and ponalrestat, on glomerular prostaglandin production and urinary albumin excretion was investigated in rats with diabetes induced by streptozotocin. It was found that both aldose reductase inhibitors, when administered from the time of induction of the diabetes, significantly decreased the raised urinary albumin excretion in the diabetic rats, although it remained elevated compared with non-diabetic rats. Glomerular prostaglandin $\mathrm{E}$ and 6-ketoprostaglandin $F_{1} \alpha$ production was significantly increased in glomeruli obtained from the diabetic rats. Inhibition of aldose reductase caused a reduction in the raised glomerular prostaglandin production, although this remained above that observed in the non-diabetic rats. Subsequent experiments were performed to determine whether the effects of the aldose reductase inhibitors could be explained by effects on glomerular filtration rate. It was found that ponalrestat, at a dose which markedly reduced urinary albumin excretion, did
\end{abstract}

not significantly affect glomerular filtration rate in nondiabetic rats, rats with untreated streptozotocin-induced diabetes and rats with diabetes partially treated with low dose insulin. Glomerular sorbitol concentrations were significantly elevated in untreated diabetic rats as early as two weeks after the induction of diabetes. It is concluded that the administration of aldose reductase inhibitors from the time of induction of diabetes significantly reduces glomerular prostaglandin production and urinary albumin excretion. The latter effect is not due to an effect on glomerular filtration rate. Increased polyol pathway activity may account in part for the increased glomerular prostaglandin production and urinary albumin excretion in early experimental diabetes.

Key words: Diabetic nephropathy, albuminuria, aldose reductase inhibitors, prostaglandins.
A number of functional and biochemical changes have been demonstrated in early diabetes in humans and in experimental animals which have been postulated to lead to the later development of the structural changes that characterise diabetic nephropathy. These include increased glomerular filtration rate (GFR) [1-13], increased urinary albumin excretion (UAE) [13-17], increased production of vasoactive prostaglandins (PGs) by renal glomeruli $[10,18-20]$, and increased glomerular sorbitol accumulation [21]. Although there are several plausible ways in which these changes could be related, the data linking these phenomena have been conflicting and confusing. For example, studies using aldose reductase inhibitors (ARI) to inhibit sorbitol accumulation have been reported to prevent the increased GFR and reduce the albuminuria seen in rats with diabetes induced by streptozotocin (STZ) [17], or to have no effect on either parameter [16], or to reduce the raised GFR but by effects apparently independent of reduction in sorbitol levels [22]. Moreover, the role of elevated $\mathrm{PG}$ production in the hyperfiltration and albuminuria seen in early diabetes in rats has been debated with conflicting conclusions $[10,18-20,23]$. Finally, although aldose reductase inhibition with sorbinil has been found to reduce glomerular PG production, it has been concluded that this is not due to aldose reductase inhibition per se [22], allowing no conclusions concerning whether increased PG production is dependent on increased activity of the aldose reductase pathway.

This manuscript addresses some of these issues. Specifically, the effect of two structurally unrelated aldose reductase inhibitors on glomerular PG production and UAE is studied. Experiments showing that effects on UAE are not due to altered GFR are also reported, indicating an influence of experimental diabetes and aldose reductase inhibition on permeability of the glomeruli to albumin independent of GFR. 
Table 1. Plasma glucose and body mass of the rats in experiment 1 (sorbinil treatment) at time of killing

\begin{tabular}{lcccc}
\hline & $\begin{array}{l}\text { Non- } \\
\text { diabetic }\end{array}$ & \multicolumn{1}{c}{$\begin{array}{l}\text { Non-diabe- Diabetic } \\
\text { tic sorbinil }\end{array}$} & \multicolumn{1}{c}{$\begin{array}{l}\text { Diabetic } \\
\text { sorbinil }\end{array}$} \\
\hline $\begin{array}{l}\text { Number } \\
\text { Plasma gluco- }\end{array}$ & 6 & 6 & 6 & 5 \\
$\begin{array}{l}\text { se (mmol/l) } \\
\text { Body mass (g) }\end{array}$ & $24.9 \pm 0.4$ & $8.0 \pm 0.4$ & $30.4 \pm 2.0^{\mathrm{a}}$ & $30.4 \pm 1.6^{\mathrm{a}}$ \\
\hline
\end{tabular}

${ }^{a} p<0.001 \mathrm{cf}$ non-diabetic

\section{Materials and methods}

\section{Maintenance of rats and induction of diabetes mellitus}

Male Sprague-Dawley rats weighing 100-120 g at the commencement of each experiment were allowed free access to commercial chow (Gr2 +, Clark, King and Co., Melbourne, Victoria, Australia) and tap water. Where indicated, diabetes was induced by a single intravenous or intraperitoneal injection of STZ (Sigma Chemical Co., St. Louis, Mo., USA), $65 \mathrm{mg} / \mathrm{kg}$, prepared freshly in trisodium citrate $100 \mathrm{mmol} / 1$, pH 4.0. Control rats were injected with vehicle alone. Diabetes was confirmed by plasma glucose concentration above $15 \mathrm{mmol} / \mathrm{l}$.

The ARI suspended in water were administered at a dose of $20 \mathrm{mg} / \mathrm{kg}$ by gavage feeding, at the same time each day. Control rats were gavage fed water. Sorbinil was generously donated by Pfizer Inc. (Groton, Conn., USA) and ponalrestat (Statil, ICI 128436; Prodiax MK538) by ICI Pharmaceuticals (Macclesfield, Cheshire, UK).

\section{Isolation and incubation of glomeruli}

Rats were stunned and decapitated, and the kidneys were quickly removed and placed in cold modified Krebs-Ringer-Bicarbonate buffer $(110.80 \mathrm{mmol} / 1 \mathrm{NaCl}, 4.87 \mathrm{mmol} / \mathrm{KCl}, 2.29 \mathrm{mmol} / \mathrm{l} \mathrm{CaCl}$, $1.22 \mathrm{mmol} / 1 \mathrm{KH}_{2} \mathrm{PO}_{4}, 1.21 \mathrm{mmol} / \mathrm{l} \mathrm{MgSO}$, $25.70 \mathrm{mmol} / 1 \mathrm{NaHCO}_{3}$, $21.05 \mathrm{mmol} / \mathrm{l} \mathrm{HEPES}, 11.50 \mathrm{mmol} / \mathrm{l}$ glucose, $350 \mathrm{mg}$ bovine serum albumin per $100 \mathrm{ml}, \mathrm{pH} 7.4$ ). The renal capsules were peeled off, the kidneys sliced longitudinally and the medulla dissected from the cortex. A mid-coronal section from a kidney was stored at $-20^{\circ} \mathrm{C}$ for subsequent sorbitol analysis. Glomeruli were isolated by differential sieving. The cortex pieces were pressed through stainless steel meshes with pore sizes 250 and $125 \mu \mathrm{m}$ and washed through with modified Krebs-Ringer-Bicarbonate buffer. Tissue resting on the bottom sieve $(75 \mu \mathrm{m})$ was collected into a plastic tube, and washed

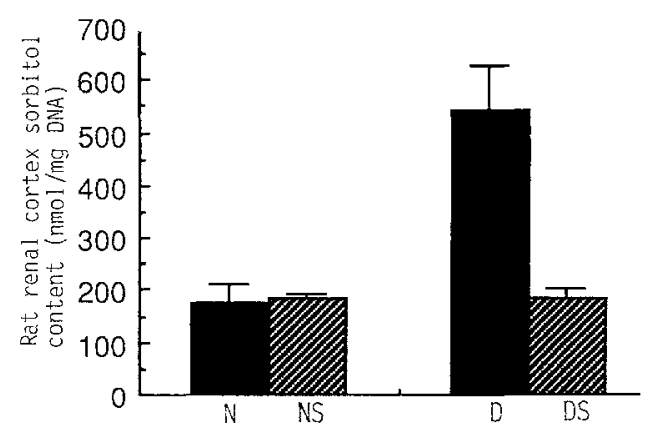

Fig. 1. Sorbitol content of renal cortex from non-diabetic $(N)$ and diabetic (D) rats fed with $20 \mathrm{mg} \cdot \mathrm{kg}^{-1} \cdot$ day $^{-1}$ sorbinil (S) or vehicle. Values shown are mean and SEM. There were six rats per group except for DS (five rats). D group was significantly higher than all the other groups $(p<0.01)$, which were not significantly different from each other

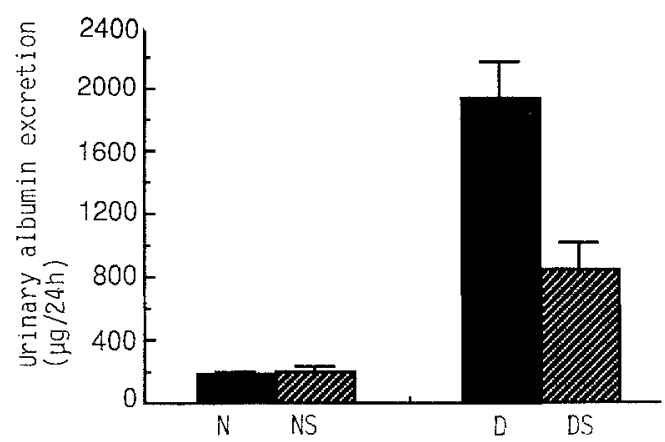

Fig. 2. Urinary albumin excretion in non-diabetic $(N)$ and diabetic (D) rats fed with $20 \mathrm{mg} \cdot \mathrm{kg}^{-1} \cdot \mathrm{day}^{-1}$ sorbinil (S) or vehicle. Values shown are mean and SEM. There were six rats per group except for DS (five rats). D group was significantly higher than $\mathrm{N}$ and NS $(p<0.001)$ and $\mathrm{DS}$ was significantly lower than $\mathrm{D}(p<0.01)$ but significantly higher than N and NS $(p<0.01)$

and centrifuged six times for one min at $1500 \mathrm{~g}$. Preparations with minimal tubule contamination $(<5 \%)$ were placed on ice for $90 \mathrm{~min}$. Aliquots of approximately 5000 glomeruli were pipetted into capped microtubes and incubated in a gentle shaking water bath at $37^{\circ} \mathrm{C}, 100$ oscillations per min for $20 \mathrm{~min}$. Arachidonic acid (Sigma Chem. Co.) was added to half the microtubes in the first experimental protocol to give a final concentration of $5 \times 10^{-5} \mathrm{~mol} / \mathrm{l}$, and angiotensin II was added to half the microtubes in the second experimental protocol to give a final concentration of $10^{-6} \mathrm{~mol} / \mathrm{l}$. The incubation was terminated after 20 min by embedding the microtubes in ice before centrifugation for $45 \mathrm{~s}$ at $15000 \mathrm{~g}$. Supernatants and pellets were separated and stored at $-20^{\circ} \mathrm{C}$ for subsequent prostanoid and DNA assays respectively.

\section{Glomerular filtration rate (GFR)}

GFR was determined using technetium $99 \mathrm{~m}$ diethylene triamine pentacetic acid (DTPA) injection, as described and validated previously $[12,24]$. The procedure is performed in conscious rats, and can be repeated in the same animals (in this case, at two weeks and four weeks).

\section{Assays}

Total PGE activity and 6-keto-PGF, $\alpha$ activity were determined by radioimmunoassay using reagents obtained from Advanced Magnetics Inc. (Cambridge, Mass., USA). The PGE antibody showed $100 \%$ cross-reactivity for $\mathrm{PGE}_{1}$ and $\mathrm{PGE}_{2}$. DNA was measured by the fluorimetric method of Downs and Wilfinger [25]. The urinary albumin concentration was measured by coated-tube radioimmunoassay [24]. The preparation of tissue for sorbitol measurement was modified from the method of Chan et al. [26]. A large volume of methanolic $\mathrm{HCl}$ was used to allow sufficient penetration of the kidney sample with homogenisation, and the amount of $\mathrm{KHCO}_{3}$ was increased to ensure the solution remained at $\mathrm{pH} 9.2$ until quantified by fluorimetry. The sorbitol assay was based on the method described by Williams-Ashman [27].

\section{Experiments performed}

Four separate experiments were performed. The first two experiments tested the effect of sorbinil and ponalrestat respectively in diabetic or control rats over a period of two and three weeks respectively. UAE and glomerular PG production were measured (in the first experiment, only PGE was measured, in the second experiment both PGE and 6-keto-PGF $1 \alpha$ ).

In the third experiment the effect of ponalrestat on GFR and UAE was tested in normal and diabetic rats over a period of two and 


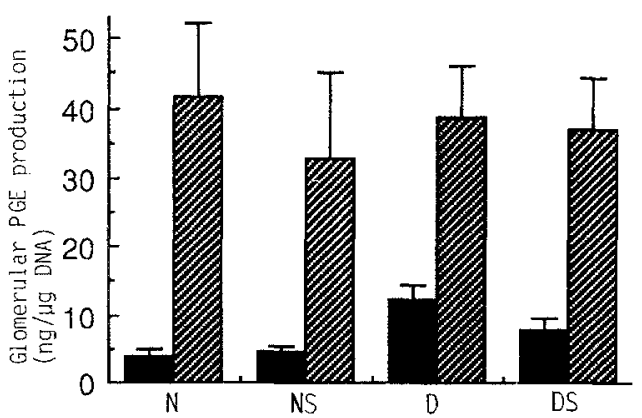

Fig. 3. Glomerular prostaglandin E (PGE) production in non-diabetic $(\mathrm{N})$ and diabetic (D) rats fed with $20 \mathrm{mg} \cdot \mathrm{kg}^{-1} \cdot \mathrm{day}^{-1}$ sorbinil (S) or vehicle. Values shown are mean and SEM. Solid bars - basal production, hatched bars - production in presence of $5 \times 10^{-5} \mathrm{~mol} / \mathrm{l}$ arachidonic acid. There were six rats per group except for DS (five rats). D group was significantly higher than N and NS $(p<0.01)$ and DS was significantly lower than D and higher than $N$ and NS $(p \leq 0.05)$

four weeks to determine whether its effects on UAE were attributable to an effect on GFR. Because partial insulin treatment has been described to prolong the period of hyperfiltration, the effect of ponalrestat on GFR and UAE was also determined in STZ-diabetic rats receiving $2 \mathrm{U} / \mathrm{kg}$ Ultratard HM (CSL-Novo, Melbourne, Victoria, Australia).

In the fourth experiment, glomeruli were harvested from control and diabetic rats after two weeks diabetes to determine whether the glomerular sorbitol concentration was elevated in diabetic rats at this time point.

\section{Statistical analysis}

All results were expressed as mean \pm SEM. Each experiment was analysed by one way analysis of variance, and where significant dif- ferences between groups were found, individual group comparisons were made using the Student's $t$-test for unpaired samples.

\section{Results}

The effect of sorbinil treatment on renal cortical sorbitol content, UAE and glomerular PGE production in non-diabetic and diabetic rats

The characteristics of the four groups of rats in the first experiment are shown in Table 1. It can be seen that the diabetic rats were significantly lighter and were markedly hyperglycaemic. Sorbinil treatment had no effect on either parameter.

The sorbitol content of the renal cortex from untreated diabetic rats was markedly elevated (Fig.1). Sorbinil had no effect on the sorbitol content of non-diabetic rats, but prevented the increase in renal cortical sorbitol in diabetic rats.

UAE was markedly elevated in untreated diabetic rats (Fig. 2). Sorbinil had no effect on UAE in non-diabetic rats, but significantly reduced the elevated UAE in the diabetic rats, although it remained significantly above that in the non-diabetic rats.

PGE production by isolated glomeruli was significantly elevated in glomeruli from untreated diabetic rats (Fig. 3). Sorbinil treatment of the diabetic rats significantly reduced the production of $\mathrm{PGE}$ by their isolated glomeruli, although this remained significantly elevated compared with the non-diabetic rats. Sorbinil had no effect on PGE production by glomeruli from non-diabetic rats. The addition of arachidonic acid $\left(5 \times 10^{-5} \mathrm{~mol} / \mathrm{l}\right)$ to the isolated glomeruli increased PGE production to a similar
Table 2. Plasma glucose, body mass, renal cortical sorbitol content, urinary albumin excretion (UAE) and kiđney mass in experiment 2 (ponalrestat treatment) at time of killing

Table 3. Production of prostaglandin $\mathrm{E}$ (PGE) and 6-keto-PGF $\alpha$ by glomeruli isolated from non-diabetic and diabetic rats treated with vehicle alone or ponalrestat

\begin{tabular}{lcccc}
\hline & Non-diabetic & $\begin{array}{l}\text { Non-diabetic/ } \\
\text { ponalrestat }\end{array}$ & Diabetic & $\begin{array}{c}\text { Diabetic/ } \\
\text { ponalrestat }\end{array}$ \\
\hline $\begin{array}{l}\text { Number } \\
\begin{array}{l}\text { Plasma glucose } \\
(\mathrm{mmol} / \mathrm{l})\end{array}\end{array}$ & 6 & \multicolumn{2}{c}{4} & 4 \\
Body mass $(\mathrm{g})$ & $324.2 \pm 6.9$ & $319.3 \pm 10.8$ & $192.5 \pm 18.2^{\mathrm{a}}$ & $174.8 \pm 25.9^{\mathrm{a}}$ \\
$\begin{array}{l}\text { Sorbitol content } \\
\text { (nmol/mg DNA) }\end{array}$ & $134 \pm 9$ & $175 \pm 8$ & $338 \pm 43^{\mathrm{a}}$ & $188 \pm 5^{\mathrm{a}, \mathrm{b}}$ \\
UAE $(\mu \mathrm{g} / 24 \mathrm{~h})$ & $61.6 \pm 6.8$ & $64.8 \pm 14.3$ & $388.0 \pm 61.6^{\mathrm{a}}$ & $115.2 \pm 34.6^{\mathrm{b}}$ \\
Kidney mass $(\mathrm{g})$ & $1.26 \pm 0.07$ & $1.22 \pm 0.06$ & $1.12 \pm 0.06$ & $0.96 \pm 0.12$ \\
$\%$ body mass & $0.39 \pm 0.02$ & $0.38 \pm 0.01$ & $0.59 \pm 0.03^{\mathrm{a}}$ & $0.56 \pm 0.02^{\mathrm{a}}$ \\
\hline
\end{tabular}

${ }^{a} p<0.001 \mathrm{cf}$ non-diabetic; ${ }^{b} p<0.001 \mathrm{cf}$ diabetic, no ponalrestat

\begin{tabular}{lrrrr}
\hline & Non-diabetic & $\begin{array}{l}\text { Non-diabeticl } \\
\text { ponalrestat }\end{array}$ & Diabetic & $\begin{array}{r}\text { Diabetic/ } \\
\text { ponalrestat }\end{array}$ \\
\hline PGE $(\mathrm{ng} / \mu \mathrm{g}$ DNA) & $3.4 \pm 0.2$ & $4.0 \pm 0.4$ & $7.4 \pm 0.4^{\mathrm{a}}$ & $5.4 \pm 0.2^{\mathrm{a}, \mathrm{b}}$ \\
Basal & $17.4 \pm 1.2$ & $15.7 \pm 1.3$ & $12.5 \pm 1.2^{\mathrm{c}}$ & $14.0 \pm 1.3$ \\
Angiotensin II $10^{-6} \mathrm{~mol} / \mathrm{l}$ & & & & \\
6-keto-PGF $\alpha(\mathrm{ng} / \mu \mathrm{g}$ DNA) & $1.6 \pm 0.3$ & $1.3 \pm 0.2$ & $4.4 \pm 0.7^{\mathrm{d}}$ & $2.7 \pm 0.2^{\mathrm{c}, \mathrm{e}}$ \\
Basal & $7.1 \pm 0.7$ & $6.5 \pm 1.0$ & $7.9 \pm 0.9$ & $6.2 \pm 1.1$ \\
\hline Angiotensin II $10^{-6} \mathrm{~mol} / 1$ &
\end{tabular}

${ }^{\mathrm{a}} p<0.001 \mathrm{cf}$ non-diabetic; ${ }^{\mathrm{b}} p<0.001 \mathrm{cf}$ diabetic; ${ }^{\mathrm{c}} p<0.05 \mathrm{cf}$ non-diabetic;

${ }^{d} p<0.01$ cf non-diabetic; ${ }^{\circ} p<0.05$ cf diabetic 
Table 4. Plasma glucose and body mass of the rats in experiment 3 . There were six rats in each group

\begin{tabular}{lllllll}
\hline & \multicolumn{3}{l}{ Week 2 } & & & Week 4 \\
\cline { 2 - 3 } \cline { 5 - 6 } & $\begin{array}{l}\text { Body mass } \\
(\mathrm{g})\end{array}$ & $\begin{array}{l}\text { Plasma glucose } \\
\mathrm{mmol} / \mathrm{l}\end{array}$ & & $\begin{array}{l}\text { Body mass } \\
(\mathrm{g})\end{array}$ & $\begin{array}{l}\text { Plasma glucose } \\
\mathrm{mmol} / \mathrm{l}\end{array}$ \\
\hline Non-diabetic & $247 \pm 6$ & $8.3 \pm 0.1$ & & $356 \pm 11$ & $7.4 \pm 0.2$ \\
Non-diabetic/ponalrestat & $255 \pm 8$ & $8.5 \pm 0.2$ & & $351 \pm 14$ & $6.7 \pm 0.2$ \\
Diabetic & $192 \pm 8^{\mathrm{a}}$ & $37.7 \pm 1.4^{\mathrm{a}}$ & & $213 \pm 5^{\mathrm{a}}$ & $34.0 \pm 1.2^{\mathrm{a}}$ \\
Diabetic/ponalrestat & $173 \pm 6^{\mathrm{a}}$ & $34.6 \pm 1.2^{\mathrm{a}}$ & & $200 \pm 6^{\mathrm{a}}$ & $32.8 \pm 0.9^{\mathrm{a}}$ \\
Diabetic/insulin & $224 \pm 5$ & $12.8 \pm 2.4$ & & $333 \pm 11$ & $18.0 \pm 2.0^{\mathrm{b}}$ \\
Diabetic/insulin/ponalrestat & $218 \pm 7$ & $19.6 \pm 1.9^{\mathrm{a}}$ & & $316 \pm 7$ & $13.8 \pm 1.6^{\mathrm{b}}$ \\
\hline
\end{tabular}

${ }^{\mathrm{a}} p<0.001 \mathrm{cf}$ non-diabetic; ${ }^{\mathrm{b}} p<0.01 \mathrm{cf}$ non-diabetic level in diabetic and non-diabetic rats treated or untreated with sorbinil.

\section{The effect of ponalrestat treatment on renal cortical sorbitol content, UAE, glomerular PGE and 6-keto-PGF $\alpha$ production and kidney size in non-diabetic and diabetic rats}

The characteristics of the four groups of rats in the second experiment are shown in Table 2. This table also shows the renal cortical sorbitol content, UAE and kidney size in the four groups. It can be seen that, as with sorbinil, ponalrestat treatment was effective in preventing the rise in the renal cortical sorbitol content in the diabetic rats. This was associated with a significant reduction in UAE in the diabetic rats treated with ponalrestat. The kidney mass and the kidney mass as a percentage of body mass was not significantly affected by ponalrestat treatment.

The production of PGE and 6-keto-PGF $\alpha$ both basally and following stimulation with angiotensin II by glomeruli isolated from the four groups of rats is shown in Table 3. It can be seen that as in the first experiment the production of PGE was increased in glomeruli from diabetic rats under basal conditions. 6-keto- $\mathrm{PGF}_{1} \alpha$ production was also increased. In glomeruli from the diabetic rats treated with ponalrestat, production of both prostanoids was reduced significantly, but remained significantly elevated above that seen in the non-diabetic rats. Incubation of the glomeruli with angiotensin II $10^{-6} \mathrm{~mol} / \mathrm{lre}-$ sulted in significant stimulation of PGE and 6-keto$\mathrm{PGF}_{1} \alpha$ production. The proportional stimulation over basal was much greater in the glomeruli from the nondiabetic rats ( $4-5$ fold) than in the diabetic rats (less than two-fold) with intermediate fold stimulation in the glomeruli from the diabetic rats treated with ponalrestat (23 fold). The production of PGE and 6-keto-PGF $\alpha$ in the presence of angiotensin II was similar in all groups, except for a significant reduction in the production of PGE in the diabetic group not treated with ponalrestat (Table 3).

\section{The relationship between $U A E$ and GFR in non-diabetic and diabetic rats with and without ponalrestat or low dose insulin treatment}

The plasma glucose and body mass of the rats in the third experiment at two weeks and four weeks are shown in Table 4. It can be seen that treatment with insulin led to normal weight gain and intermediate plasma glucose between the non-insulin treated diabetic rats and the nondiabetic rats.

The UAE in the four groups of rats at the two time points is shown in Figure 4 and the GFR in Figure 5. It is apparent that insulin treatment prevented the progressive rise in UAE. As in the second experiment (Table 2), ponalrestat treatment decreased the increase in UAE in the non-insulin-treated diabetic rats, but did not restore it to the level seen in non-diabetic rats.

Normalisation of the UAE for the GFR (Table 5) showed that the diabetic rats still exhibited a marked increase in UAE for a given GFR. Ponalrestat treatment of diabetic rats restored the normalised UAE to that of non-

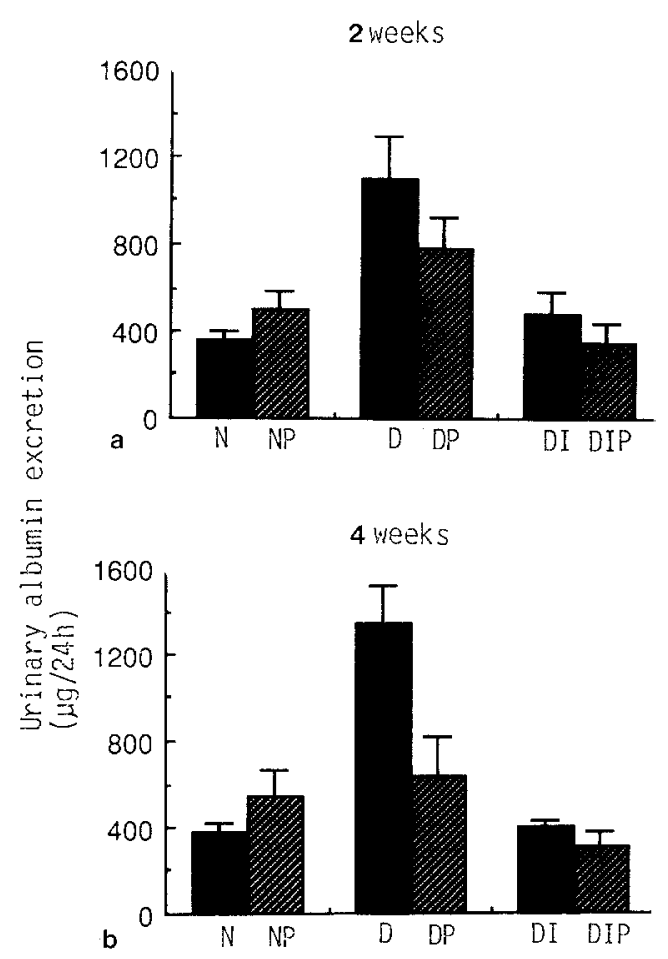

Fig.4a, b. Urinary albumin excretion in non-diabetic $(N)$, and diabetic (D) rats fed $20 \mathrm{mg} \cdot \mathrm{kg}^{-1} \cdot \mathrm{day}^{-1}$ ponalrestat $(\mathrm{P})$ or vehicle, some which were injected with Ultratard HM insulin, $2 \mathrm{U} / \mathrm{kg}$ body weight (I). There were six rats per group. Values are shown at 2 weeks (a) and 4 weeks (b) after induction of diabetes. At 2 weeks, only the untreated diabetic group (D) had significantly elevated urinary albumin excretion ( $p<0.01 \mathrm{cf} N$ ). At 4 weeks, the urinary albumin excretion in the untreated diabetic group (D) was significantly increased $(p<0.01 \mathrm{cf} N)$ and that in the ponalrestat-treated diabetic group (DP) was significantly decreased compared with the untreated diabetic group $(p<0.05)$ 


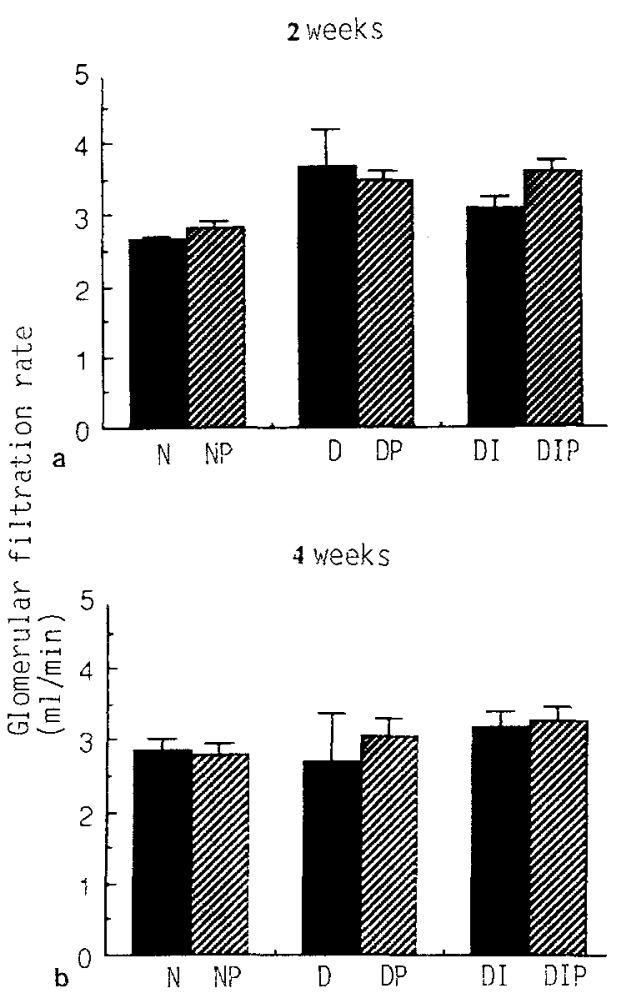

Fig.5a,b. Glomerular filtration rate (GFR) in the six groups of rats described in Figure 4. There was no significant effect of ponalrestat (P) treatment in the diabetic (D) rats, whether insulin treated (I) or not. At two weeks (a), the diabetic rats as a group, either not treated with insulin (D and DP) or treated with insulin (DI and DIP) had significantly elevated GFR compared with the non-diabetic rats ( $N$ and NP) $(p<0.05)$. At 4 weeks (bottom panel), only the insulin-treated diabetic rats (DI and DIP) had elevated GFR compared with the non-diabetic rats $(\mathrm{N}$ and NP) $(p<0.05)$

diabetic rats. The UAE of the insulin-treated diabetic rats normalised for GFR was not elevated above that of the non-diabetic rats.

The GFR was not affected by ponalrestat in the nondiabetic rats, the diabetic rats or the insulin-treated diabetic rats (Fig. 5). The GFR in both the non-insulintreated and the insulin-treated diabetic rats was elevated above that of the non-diabetic rats at two weeks, but only that of the insulin-treated diabetic rats was elevated at 4 weeks. However, when the GFR was expressed in terms of body mass, the GFR of the non-insulin treated diabetic rats was significantly elevated compared with the nondiabetic rats at four weeks (Table 5). There was no tendency for ponalrestat to reduce the GFR expressed in relation to body weight (Table 5). There was no difference in GFR normalised for kidney weight between any of the six groups of rats (data not shown).

\section{Glomerular sorbitol content in non-diabetic rats and rats after 2 weeks of diabetes induced by streptozotocin}

The mean glomerular sorbitol content in four separate experiments, each comprising pooled glomeruli from six rats was $23.8 \pm 3.6 \mathrm{nmol} / \mathrm{mg}$ DNA for non-diabetic rats and $34.9 \pm 3.3 \mathrm{nmol} / \mathrm{mg}$ DNA $(p<0.05)$ for diabetic rats injected with STZ two weeks before.
Table 5. Urinary albumin excretion (UAE) normalised for glomerular filtration rate (GFR) and GFR normalised for body mass in experiment 3. Mean $\pm S E M$ are shown. There were six rats in each group

\begin{tabular}{llc}
\hline & $\begin{array}{l}\mathrm{UAE} / \mathrm{GFR} \\
\mu \mathrm{g} / \mathrm{ml} \cdot \mathrm{min}^{-1}\end{array}$ & $\begin{array}{l}\mathrm{GFR} / \mathrm{kg} \text { body } \\
\mathrm{mass} \mathrm{ml} \cdot \mathrm{min}^{-1} / \mathrm{kg}\end{array}$ \\
\hline Non-diabetic & $166 \pm 31$ & $8.6 \pm 0.5$ \\
Non-diabetic/ponalrestat & $222 \pm 38$ & $8.3 \pm 0.6$ \\
Diabetic & $610 \pm 113^{\mathrm{a}}$ & $11.9 \pm 1.0^{\mathrm{b}}$ \\
Diabetic/ponalrestat & $191 \pm 46$ & $14.5 \pm 1.2^{\mathrm{a}}$ \\
Diabetic/insulin & $157 \pm 35$ & $10.0 \pm 0.8$ \\
Diabetic/insulin/ponalrestat & $121 \pm 31$ & $10.8 \pm 0.6^{\mathrm{c}}$ \\
\hline
\end{tabular}

${ }^{a} p<0.01 \mathrm{cf}$ non-diabetic group;

b $p<0.02$ cf non-diabetic and non-diabetic/ponalrestat groups, but not significantly different from diabetic/ponalrestat group;

c $p<0.05$ cf non-diabetic/ponalrestat group

\section{Discussion}

This study has confirmed that inhibition of the enzyme aldose reductase by two structurally unrelated compounds partially prevents the increase in UAE observed in rats with diabetes induced by STZ $[15,17,21,22]$. It has also confirmed the findings of Craven et al. [22] that the enhanced PG production by glomeruli isolated from STZ diabetic rats is reduced by treatment with ARI. No effect of an ARI (in this case ponalrestat) on GFR was observed. Hyperfiltration was seen in rats after two weeks of STZ diabetes, but this had subsided by four weeks when expressed on a per animal basis, although it remained elevated when corrected for body weight. Early hyperfiltration with subsequent fall to non-diabetic levels has been described previously in diabetic rats [4, 6-8]. The effect of suboptimal insulin treatment to prolong the hyperfiltration has also been observed previously $[4,6,8]$. The fact that insulin treatment of STZ-diabetic rats prevented the rise in UAE confirms that the increased UAE is not due to a toxic renal effect of STZ unrelated to diabetes. Unlike Tilton et al. [17] and Bank et al. [28], but similarly to Daniel and Hostetter [16] and Mauer et al. [29], we found no effect of an ARI (in this case ponalrestat) on GFR [17]. The reason for this is not clear, but may be related to the type of ARI, its dose, the method of measurement of GFR or many other variables. Moreover, sorbinil appears to decrease single nephron blood flow but increase filtration fraction in STZ-diabetic rats [28], and the balance between these two effects could vary in different experimental settings producing different net effects on GFR. However, in the present experiments, the clear lack of effect on GFR, with the simultaneous marked effect in diminishing UAE clearly establishes that the effect of the ARI on UAE is not mediated solely by an effect on GFR. This conclusion is supported by the data relating to the effect of suboptimal insulin therapy. As shown previously $[6,8]$, this prolongs the period of hyperfiltration, but prevents the early increase in UAE. Moreover, the dissociation of hyperfiltration from increased UAE in the untreated diabetic rats is further reinforced by expressing the $\mathrm{UAE}$ normalised according to GFR (Table 5). When expressed in this way, UAE remains markedly elevated in the un- 
treated diabetic rats. It is in the non-diabetic range in the ponalrestat-treated diabetic rats.

In agreement with Craven et al. [22], we have shown that sorbinil diminishes the increased glomerular PG production. However, we have been able to clarify some confusing aspects of the previous study. First, by showing that two structurally unrelated ARI shared this effect, the case for the effect being related to aldose reductase inhibition is strengthened. Moreover, unlike Craven et al. [22], it was demonstrated that the glomerular sorbitol content is already elevated after two weeks of diabetes, making it likely (but certainly not proving) that the effect of the ARI was linked to inhibition of sorbitol formation (or some other aspect of inhibition of the aldose reductase pathway). The increased basal PGE and 6-keto- $\mathrm{PGF}_{1} \alpha$ production, and the relatively small effect of exogenous arachidonic acid or angiotensin II on PG production in the glomeruli from the diabetic rats supports the conclusion of Craven et al. [30] that the increased glomerular PG synthesis in diabetes is due to increased arachidonate availability due to endogenous phospholipase $\mathrm{A}_{2}$ activation. If arachidonic acid is provided exogenously (as in Fig.3), or phospholipase $A_{2}$ activated by exogenous angiotensin II (as in Table 3 ), the PG production from diabetic glomeruli is not greater than from control glomeruli.

The lack of correlation between the effect of ponalrestat on glomerular PG production (which is decreased) and on GFR (which is not affected) suggests that factors other than or in addition to PGs may mediate the hyperfiltration of diabetes, although without knowledge of the concentration response curve for endogenous PGs and GFR under the conditions of the study, this conclusion must be tentative. Obviously the relationship of glomerular PGs to GFR in diabetes is complex, as reflected by previous reports which have had conflicting results $[10,20,23]$.

In conclusion, the current study has shown that two structurally unrelated ARI reduce the elevated UAE observed in rats with short-term (two to four weeks) STZ-induced diabetes. This effect is apparently due to an effect on glomerular permeability rather than on GFR, which, in this study, was unaffected. Both agents reduced the increased glomerular PG production in the diabetic rats, but did not restore it to the level of the non-diabetic rats. It is thus clear that there are links between aldose reductase pathway activity, glomerular PG production and UAE, but the nature of the links, and cause and effect relationships remain to be established. It is also not clear whether the effect of the ARI is due to their effect on sorbitol levels, alteration of the cellular NADP:NADPH ratio or to effects unrelated to aldose reductase inhibition. The last possibility seems unlikely in view of the similar effects of structurally dissimilar ARI. The relevance of partial reversal of the early increased albumin excretion in induced acute diabetes in rats to the prevention of diabetic nephropathy in humans is also uncertain. However, despite all these reservations, the data support the concept that increased aldose reductase pathway activity is linked to the abnormalities of PG synthesis and albumin excretion observed in early diabetes, and that the changes are partially preventable by pharmacological agents.
Acknowledgements. This work was supported by the Juvenile Diabetes Foundation of Australia and the Juvenile Diabetes Foundation International, the Hoechst Australia Diabetes Research Fund, the John Claude Kellion Foundation and the National Health and Medical Research Council of Australia. We thank Pfizer Central Research and ICI Pharmaceuticals for supply of sorbinil and ponalrestat respectively.

\section{References}

1. Stalder G, Schmid R (1959) Severe functional disorders of glomerular capillaries and renal hemodynamics in treated diabetes mellitus during childhood. Ann Pediatr 193: 129-138

2. Mogensen CE (1971) Glomerular filtration rate and renal plasma flow in short-term and long-term juvenile diabetes mellitus. Scand J Clin Lab Invest 28: 91-100

3. Gartner K (1978) Glomerular hyperfiltration during the onset of diabetes mellitus in two strains of diabetic mice (C57BL/6J $\mathrm{db} / \mathrm{db}$ ) and C57BL/KsJ db/db). Diabetologia 15: 59-63

4. Carney SL, Wong NLM, Dirks JH (1979) Acute effects of streptozotocin on rat renal function. J Lab Clin Med 93: 950-960

5. Christiansen JS, Gammelgaard J, Frandsen M, Parving H-H (1981) Increased kidney size, glomerular filtration rate and renal plasma flow in short-term insulin dependent diabetes. Diabetologia 20: 451-456

6. Hostetter TH, Troy JL, Brenner BM (1981) Glomerular haemodynamics in experimental diabetes mellitus. Kidney Int 19: 410415

7. Jensen PK, Christiansen JS, Steven K, Parving H-H (1981) Renal function in streptozotocin-diabetic rats. Diabetologia 21: 409-414

8. Michels LD, Davidman M, Keane WF (1981) Determinants of glomerular filtration and plasma flow in experimental diabetic rats. J Lab Clin Med 98: 869-885

9. Mauer SM, Steffes MW, Ellis EN, Sutherland DER, Brown DM, Goetz FC (1984) Structural-functional relationships in diabetic nephropathy. J Clin Invest 74: 1143-1155

10. Craven PA, Caines MA, DeRubertis FR (1987) Sequential alterations in glomerular prostaglandin and thromboxane synthesis in diabetic rats: relationship to the hyperfiltration of early diabetes. Metabolism 36: 95-103

11. Pugliese G, Tilton RG, Speedy A, Chang K, Santarelli E, Province MA, Eades D, Sherman WR, Williamson JR (1989) Effects of very mild versus overt diabetes on vascular haemodynamics and barrier function in rats. Diabetologia 32: 845-847

12. O'Brien RC, Allen TJ, Cooper ME, Bach L, Jerums G (1988) Glomerular filtration in early diabetes. Diabetes Complications 2:8-11

13. Mogensen CE (1976) Renal function in diabetes. Diabetes 25; 872-879

14. Mauer SM, Brown DM, Matas AJ, Steffes MW (1978) Effects of pancreatic islet transplantation on the increased urinary albumin excretion rates in intact and uninephrectomized rats with diabetes mellitus. Diabetes 27:959-964

15. Beyer-Mears A, Cruz E, Edelist T, Varagiannis E (1986) Diminished proteinuria in diabetes mellitus by sorbinil, an aldose reductase inhibitor. Pharmacology 32: 52-60

16. Daniel BS, Hostetter TH (1989) Aldose reductase inhibition and glomerular abnormalities in diabetic rats. Diabetes 38: $981-$ 986

17. Tilton RG, Chang K, Pugliese G, Eades DM et al. (1989) Prevention of hemodynamic and vascular albumin filtration changes in diabetic rats by aldose reductase inhibitors. Diabetes 37: $1258-1270$

18. Kreisberg JI, Patel PY (1983) The effects of insulin, glucose and diabetes on prostaglandin production by rat kidney glomeruli and cultured glomerular mesangial cells. Prostaglandins Leukot Med 11: 431-432 
19. Schambelan M, Blake S, Sraer J, Bens M, Nivez M-P, Wahbe F (1985) Increased prostaglandin production by glomeruli isolated from rats with streptozotocin-induced diabetes mellitus. J Clin Invest 75 : 404-412

20. Kirschenbaum MA, Chaudhari A (1986) Effect of experimental diabetes on glomerular filtration rate and glomerular prostaglandin production in the rat. Mineral Electrolyte Metab 12:353-355

21. Beyer-Mears A, Ku L, Cohen MP (1984) Glomerular polyol accumulation in diabetes and its prevention by oral sorbinil. Diabetes 33: 604-607

22. Craven PA, De Rubertis FR (1989) Sorbinil suppresses glomerular prostaglandin production in the streptozotocin diabetic rat. Metabolism 38: 649-654

23. Barnett R, Scharschmidt L, Ko Y-H, Schlondorff D (1987) Comparison of glomerular and mesangial prostaglandin synthesis and glomerular contraction in two rat models of diabetes mellitus. Diabetes 36: 1468-1475

24. Allen TJ, Cooper ME, O'Brien RC, Bach L, Jackson B, Jerums $G$ (1990) Glomerular filtration rate in the streptozotocin diabetic rat: the role of exchangeable sodium, vasoactive hormones and insulin therapy. Diabetes 39: 1182-1190

25. Downs TR, Wilfinger WW (1983) Fluorimetric quantification of DNA in cells and tissue. Anal Biochem 131:538-547

26. Chan AWK, Burch HB, Alvey TR, Lowry OH (1975) A quantitative histochemical approach to renal transport. I. Aspartate and glutamate. Am J Physiol 229: 1034-1044
27. Williams-Ashman GH (1965) D-Sorbitol. In: Bergmeyer HU (ed) Methods of enzymatic analysis. Academic Press, New York, pp 167-170

28. Bank N, Mower P, Aynedjian HS, Wilkes BM, Silverman S (1989) Sorbinil prevents glomerular hyperfusion in diabetic rats. Am J Physiol 256: F1000-F1006

29. Mauer SM, Steffes MW, Azar S, Brown DM (1989) Effects of sorbinil on glomerular structure and function in long-term diabetic rats. Diabetes 38: 839-846

30. Craven PA, Patterson MC, DeRubertis FR (1988) Role of enhanced arachidonate availability through phospholipase A2 pathway in mediation of increased prostaglandin synthesis by glomeruli from diabetic rats. Diabetes 37: 429-435

Received: 24 July 1990

and in revised form: 28 November 1990

Prof. R. G.Larkins

University of Melbourne

Department of Medicine

Royal Melbourne Hospital

Victoria 3050

Australia 